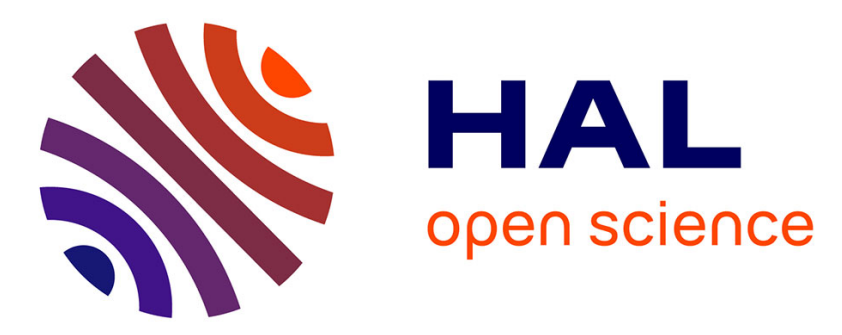

\title{
Robustness study of a fast protection method based on the gate-charge dedicated for SiC MOSFETs power device
}

Yazan Barazi, Frédéric Richardeau, Nicolas Rouger, Jean-Marc Blaquière

\section{- To cite this version:}

Yazan Barazi, Frédéric Richardeau, Nicolas Rouger, Jean-Marc Blaquière. Robustness study of a fast protection method based on the gate-charge dedicated for SiC MOSFETs power device. Microelectronics Reliability, 2021, pp.114246. 10.1016/j.microrel.2021.114246 . hal-03381405

\author{
HAL Id: hal-03381405 \\ https://hal.science/hal-03381405
}

Submitted on 16 Oct 2021

HAL is a multi-disciplinary open access archive for the deposit and dissemination of scientific research documents, whether they are published or not. The documents may come from teaching and research institutions in France or abroad, or from public or private research centers.
L'archive ouverte pluridisciplinaire HAL, est destinée au dépôt et à la diffusion de documents scientifiques de niveau recherche, publiés ou non, émanant des établissements d'enseignement et de recherche français ou étrangers, des laboratoires publics ou privés. 


\title{
Robustness study of a fast protection method based on the gate-charge dedicated for SiC MOSFETs power device
}

\author{
Yazan Barazi, Frédéric Richardeau, Nicolas Rouger, Jean-Marc Blaquière
}

Laplace, University of Toulouse, CNRS, Toulouse INP, UPS, Toulouse, France

\begin{abstract}
This paper focuses on the extensive robustness validation of a gate charge detection method designed for $\mathrm{SiC}$ MOSFETs under short-circuit operation, and, in terms of failure-modes. The benefits of having a fast (submicrosecond $-150 \mathrm{~ns}$ ) detection method is illustrated by a $1 \mathrm{D}$ thermo-metallurgical simulation. This method is integrated owing to an optimized SMD/PCB technology (Surface-Mount Device/ Printed Circuit Board).
\end{abstract}

\section{Introduction}

The silicon carbide ( $\mathrm{SiC}$ ) MOSFETs have much better physical characteristics than Silicon. And, SiC MOSFETs offer several advantages such as low switching losses, higher switching frequencies, and high temperature stability, which makes them an alternative solution of Silicon IGBTs or SJMOSFETs [1]. SiC MOSFETs are taking over different markets, where they are found in different applications, especially automotive applications. However, short-circuit (SC) robustness is a key application requirement for power semiconductor devices. The short-circuit (SC) withstanding time ( $\left.\mathrm{T}_{\text {SCWT }}\right)$ of SiC MOSFETs is lower than silicon devices [2], within $\mathrm{t}_{\mathrm{SC}}=2 \mu \mathrm{s}$, [3] against $\mathrm{t}_{\mathrm{SC}}=10 \mu \mathrm{s}$ for Si IGBTs.

Many kinds of SC detection methods have been demonstrated for Silicon IGBTs [4] and $\mathrm{SiC}$ MOSFETs [5,6]. Most of the proposed techniques rely on the drain-source high-voltage or direct current sensing. Those techniques are more suitable for bipolar transistors such as IGBTs, and on the other hand they are limited due to the use of a highvoltage rating diode or using special sense-FET SiC devices [7].

This detection method is proposed in order to pile on exciting detection methods and to fill the present gap, as well as, to answer to several problematics faced nowadays by $\mathrm{SiC}$ MOSFETs. This paper proposes an original 2D diagnosis [8] detection method which is the best candidate to minimize the detection timing. The studied method depends on the fast integration of the gate current, the gate charge sequence at turn-on. The gate charge method already proved interesting results for $\mathrm{Si}$ IGBTs [9] but unclear results for $\mathrm{SiC}$ MOSFETs in terms of performances and practical PCB integration [10]. This study validates experimentally the gate charge method and fault-management for SiC MOSFETs embedded circuit in real full-voltage operation. This method is an adapted detection method, which depends on the gate charge variation on the switching cycle, between normal operation and short-mode. This method detects as early as possible the SC and turn softly the device off.

Power semiconductors devices are exposed to several types of short circuits. In summary, internal Hard switching fault (HSF, SC type1) and external fault under load (FUL, SC type2) are the two main fault behaviors. HSF occurs when the switch turns on with a permanent full bus voltage across itself typically caused by faulted control signals. FUL occurs when the device is already in on-state and an external short-circuit occurs. HSF and FUL can be distinguished by the presence or not of a dv/dt on the drain source of the MOSFETs. In all cases, MOSFETs saturates at high current density leading to a thermal dynamic source of heat in a few microseconds for the least robust components. The scope of this study is limited to HSF mode.

\section{Fast detection method}

\subsection{The benefits of a sub-microsecond detection}

In fact, the detection methods used nowadays in the industry require the measurement of $\mathrm{V}_{\mathrm{DS}}$. Therefore, the measurement of a high voltage involves different problems such as noise, high $\mathrm{dV} / \mathrm{dt}$, high-voltage components and over-cost to protect the control circuit, etc... The well-known detection method is the desaturation method and it requires a high-voltage diode for sensing, as well as, a blanking time. Moreover, the blanking time increases the protection time, which can cause the device to undergo more thermal stress at high short-circuit SC drain current. In order to support this, a thermal modelling and simulation of the chip temperature is carried out, Fig.1., which shows different thermal levels where the device undergoes different stress levels and corresponding failure-modes. The important stress level is the first one where the $\mathrm{SiO}_{2}$ strength is reached around $600 \mathrm{~K}$ and the device goes through mechanical stress, or even visible mechanical 


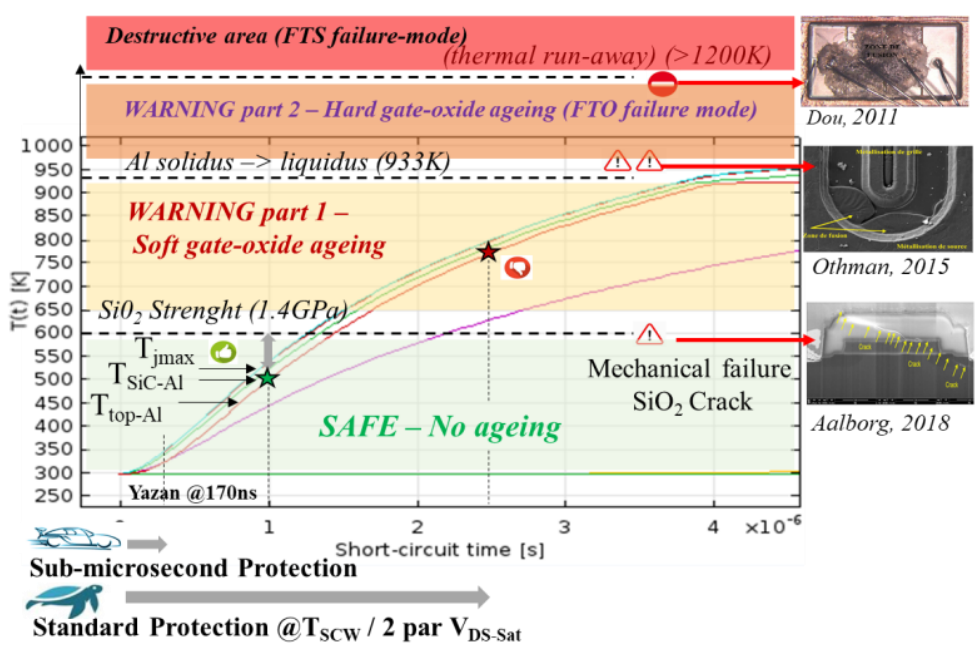

Fig. 1. 1D electro-thermal-metallurgical (Al) simulation highlighting different stress levels. [11,12,13]

failures [11]. Afterwards the device enters an ageing region, where the gate starts to weaken until the devices reaches $\mathrm{Al}$ solidus to liquidus temperature range, 933K. Above this temperature, the device shows two failure modes: gate-damage also called Fail-to-open 'FTO' mode or thermal-runaway and BJT region latch-up giving the Fail-to-short 'FTS' mode.

Using the desaturation method; which detects the

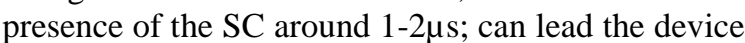
into the ageing region. Therefore, even if the power device is protected, the device will not withstand several SC due to the accumulation of the nonvisible damage brought by the thermal and physical stress. On the other hand, by protecting rapidly the device under $1 \mu \mathrm{s}$, its reduces the physical and thermal stress on the oxide of the SiC MOSFET, which allows a longer operation lifetime.

\subsection{Gate charge method under Hard Switch Fault}

This study is focused in short-circuit under Hard Switch Fault 'HSF', whose fault dynamic is faster than Fault Under load 'FUL' one. In the literature there are different architectures proposed for the gate charge method. In this study the circuit is quite the same in the concept. This gate charge method does not require high voltage diode for sensing or setting a detection period as the desaturation method. Moreover, this method has also, potentially, a high SNR. In the principle, this method requires a resettable integrator to estimate the amount of gate charge $\mathrm{Q}_{\mathrm{G}}$; and two comparators. The first comparator is to distinguish the difference between the charge amount under short circuit $\mathrm{Q}_{\mathrm{G}-\mathrm{SC}}$ and normal turn-on (NTO) $\mathrm{Q}_{\mathrm{G}-\mathrm{NTO}}$; the second comparator comes to create a reading flag using only $\mathrm{V}_{\mathrm{GS}}$ signal threshold crossing [14] and therefore a blanking time is not required. Fig.2.(a). summarizes in a $2 \mathrm{D}$ diagram the gate charge amount under NTO and $\mathrm{SC}-\mathrm{HSF}$ as a function of $\mathrm{V}_{\mathrm{GS}}$.

The validation of the gate charge method has been presented in [15]. And in order to furthermore study the robustness of the designed circuit, the same test presented in Fig.2.(b) has been led. The circuit in fig.2(b) was proposed using on the low side a $1.2 \mathrm{kV}$ $80 \mathrm{~m} \Omega$, C2M0080120D gen. II SiC MOSFET transistor, and on the high side a SiC 600V SBD (Schottky barrier diode) with a coreless inductor of $270 \mu \mathrm{H}$ as the load for the normal operation. A copper short-strap across the high side switch is used in order to get the HSF mode. The gate driver used is a 3-state fast buffer, which allows a high impedance configuration. The dedicated and optimized $\mathrm{SMD} / \mathrm{PCB}$ circuit was implemented in the power test bench as a plugging board. Low voltage signals (as $\mathrm{V}_{\mathrm{GS}}$ and $\mathrm{V}_{\text {Drv }}$ ) are mostly measured with selfcompensated voltage probes $(300 \mathrm{~V}$ and $1 \mathrm{GHz}$ bandwidth (BW) Tektronix TPP1000). High voltages (as $\left.\mathrm{V}_{\mathrm{DS}}\right)$ are typically measured with a probe $(1000 \mathrm{~V}$ and $800 \mathrm{MHz}$ BW Tektronix TPP0850). The current is measured through a $2 \mathrm{GHz}$ coaxial shunt.

(a)

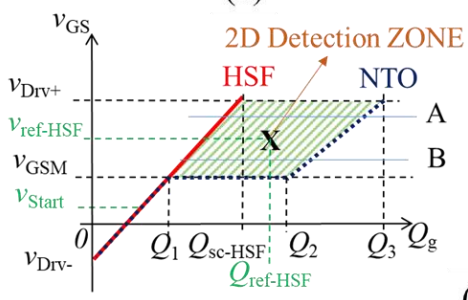

(b)

(c)

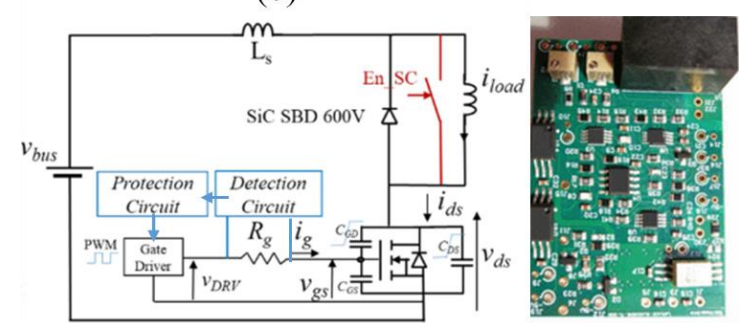

Fig.2. (a). Gate Charge characterization under NTO and HSF. (b). Circuit under test. Ls: Stray inductance. (c). view of the detection circuit, $3.5 \mathrm{~cm} * 5.3 \mathrm{~cm}$.

\section{Robustness study under different parameters 3.1. VBus variation:}

For the first robustness test, $R_{G}$ is fixed at $10 \Omega$ and $\mathrm{V}_{\text {Bus }}$ was increased with a $150 \mathrm{~V}$ step towards $600 \mathrm{~V}$, as shown in Fig.3. As presented in Fig.3. (a) under 
NTO, the device behaves normally with no interferences from the gate charge circuit. The drain current is around $15 \mathrm{~A}$ (The current scale is big in order to be able to compare the waveforms under $\mathrm{SC}$ ), and $\mathrm{dV} / \mathrm{dt}$ is equal to $32 \mathrm{~V} / \mathrm{ns}$. On the other hand, under SC-HSF the detection and protection are assured for different $\mathrm{V}_{\text {Bus. }}$. The protection time under $50 \mathrm{~V}, 150 \mathrm{~V}$ and $300 \mathrm{~V}$ is around $171 \mathrm{~ns}$, where under $450 \mathrm{~V}$ and $600 \mathrm{~V}$ is around $158 \mathrm{~ns}$. One should note as well, that ISC-MAX @600V is limited to 151A (68\%) instead of 220A without any protection, as presented in fig.4, Tab.1. In order to illustrate the difference in gate charge amount under SC-HSF and NTO, Fig.5 is presented. The figure displays the image of $\mathrm{V}_{\mathrm{GS}}$, which represents the voltage $\mathrm{V}_{\mathrm{GS}}$ adapted to $5 \mathrm{~V}$ supply functions, therefore this voltage is compared with a reference level $V_{\text {Ref }}$ higher than the Miller plateau. The figure presents as well the gate charge quantity under SC-HSF and NTO, and in order to differentiate between both operations a threshold level is set $Q_{\text {Ref. }}$ This configuration set of the references will activate the detection.
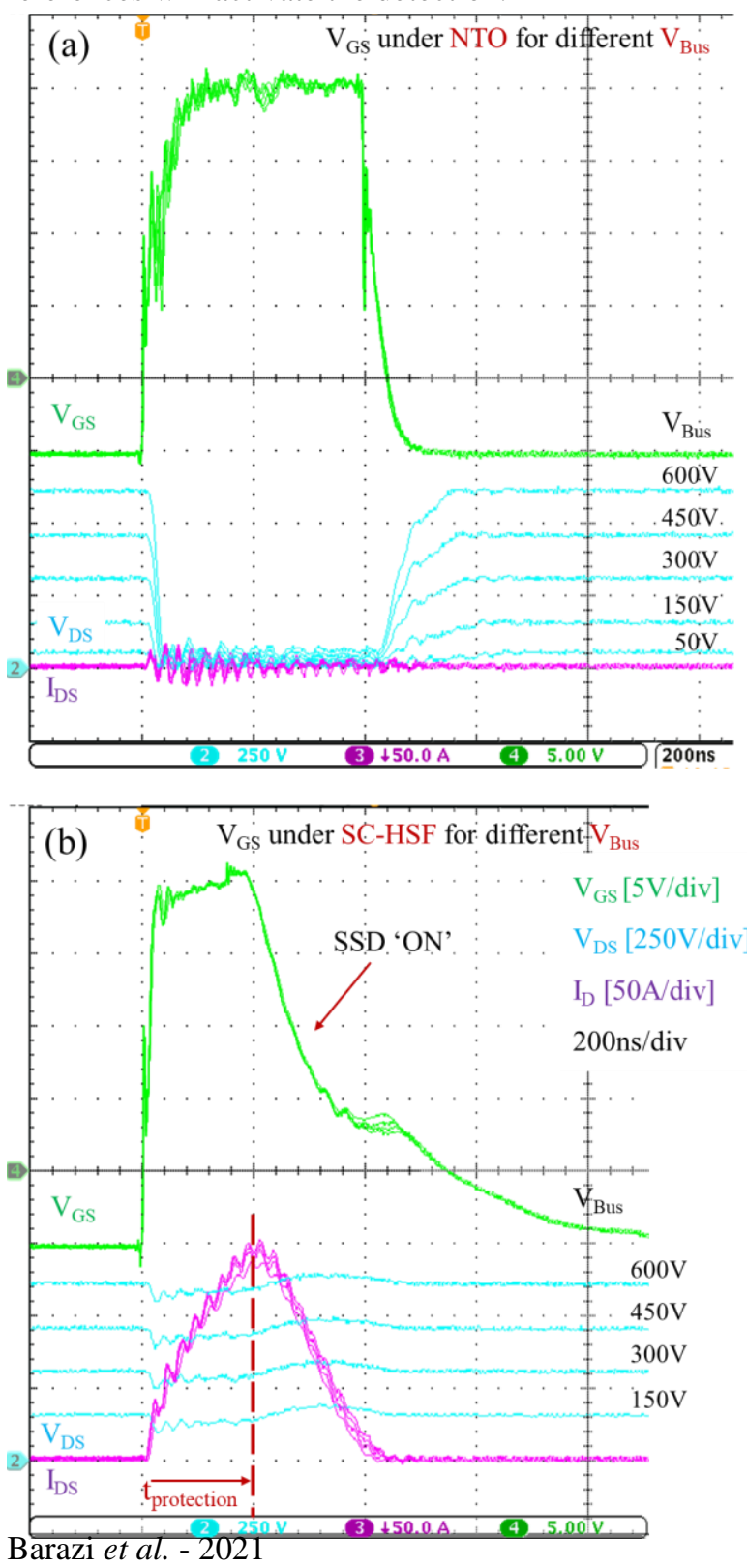

Fig. 3. Oscilloscope waveforms of the gate charge detection circuit with protection (a). under NTO. (b). under SC-HSF. @600V, $\mathrm{R}_{\mathrm{G}}=10 \Omega, \mathrm{V}_{\mathrm{Drv}}=-5 / 20 \mathrm{~V}$.

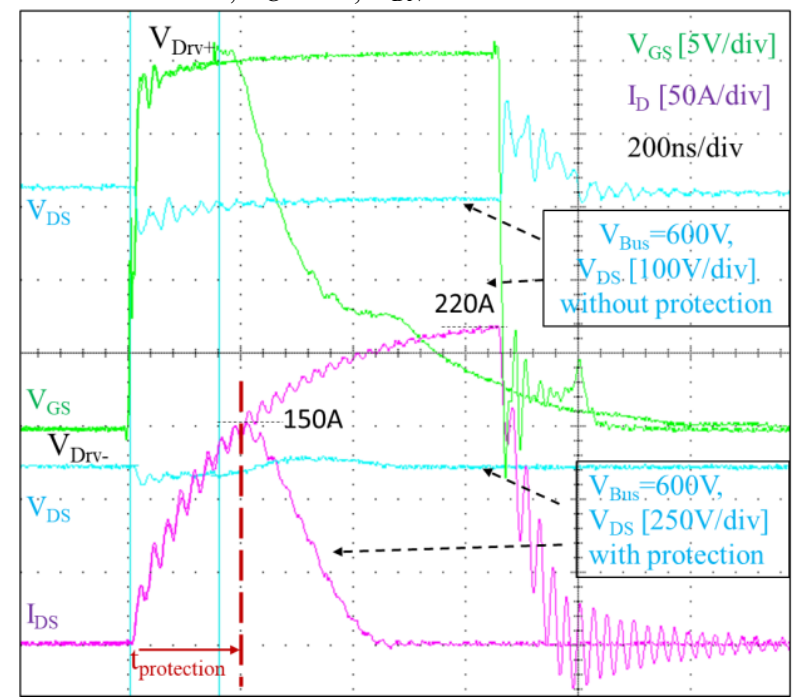

Fig. 4. Oscilloscope waveforms of the device under SC with and without protection. @600V, $\mathrm{R}_{\mathrm{G}}=10 \Omega, \mathrm{V}_{\mathrm{Drv}}=$ $5 / 20 \mathrm{~V}$.

Table 1. ISC-Max under different $\mathrm{V}_{\mathrm{DS}}$.

\begin{tabular}{ccccc}
\hline VDS & $\begin{array}{c}\text { Isc-Max without } \\
\text { protection }\end{array}$ & $\begin{array}{c}\text { IsC-Max } \\
\text { protection }\end{array}$ & Ratio \% & $\begin{array}{c}\text { Protection } \\
\text { time }\end{array}$ \\
\hline $50 \mathrm{~V}$ & $133 \mathrm{~A}$ & $110 \mathrm{~A}$ & $82 \%$ & $183 \mathrm{~ns}$ \\
$150 \mathrm{~V}$ & $180 \mathrm{~A}$ & $135 \mathrm{~A}$ & $75 \%$ & $171 \mathrm{~ns}$ \\
$300 \mathrm{~V}$ & $202 \mathrm{~A}$ & $139 \mathrm{~A}$ & $69 \%$ & $171 \mathrm{~ns}$ \\
$450 \mathrm{~V}$ & $213 \mathrm{~A}$ & $139 \mathrm{~A}$ & $65 \%$ & $158 \mathrm{~ns}$ \\
$600 \mathrm{~V}$ & $220 \mathrm{~A}$ & $151 \mathrm{~A}$ & $68 \%$ & $158 \mathrm{~ns}$
\end{tabular}

*Ratio\%: ISC-Max-Protection / ISC-Max-Without-Protection $* 100$

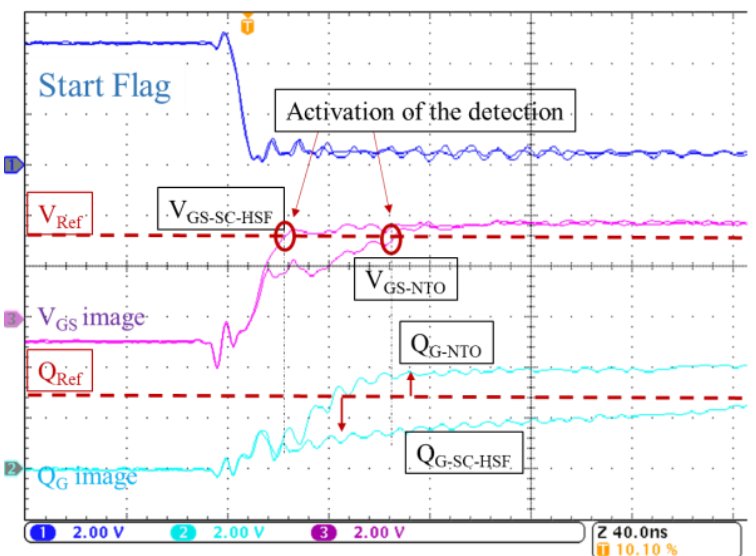

Fig.5. Integrator output " $\mathrm{Q}_{\mathrm{G}}$ " under $\mathrm{NTO}$ and SC-HSF operation @600V, $\mathrm{R}_{\mathrm{G}}=10 \Omega, \mathrm{C} 2 \mathrm{M} 0080120 \mathrm{D}, \mathrm{V}_{\mathrm{Drv}}=$ $5 / 20 \mathrm{~V}$, ILoad-NTO=15A.

\subsection{ILoad variation: (robustness in normal operation: no unwanted detection)}

In order to increase the drain current, the pulse is increased. The used test in this configuration is a double pulse method. As presented in Fig.6. the device does not show any false protection/detection. Different inductances have been tested as well. $\mathrm{dV} / \mathrm{dt}$ at $600 \mathrm{~V}$ decreases to $23 \mathrm{~V} / \mathrm{ns}$. And the drain current 
in the second pulse increases as well with the bus voltage increase: $\left(\mathrm{I}_{\mathrm{D}-\mathrm{Max}}=10 \mathrm{~A} @ 50 \mathrm{~V}, \mathrm{I}_{\mathrm{D}-\mathrm{Max}}=20 \mathrm{~A}\right.$ @150V, I $\mathrm{D}_{\mathrm{D}-\mathrm{Max}}=31 \mathrm{~A} @ 300 \mathrm{~V}, \mathrm{I}_{\mathrm{D}-\mathrm{Max}}=46 \mathrm{~A} @ 450 \mathrm{~V}$, $\left.\mathrm{I}_{\mathrm{D}-\mathrm{Max}}=60 \mathrm{~A} @ 600 \mathrm{~V}\right)$.

The evolution of the gate charge amount of the second pulse at different $\mathrm{V}_{\text {Bus }}$ is presented in Fig.7. The increase of the plateau Miller does not affect the detection: no unwanted detection appears that's confirm the global robustness in normal operation. Analytical Gate charge characteristics under different parameters variations are presented (fig.8, [16]) in order to support the study of fig.7.

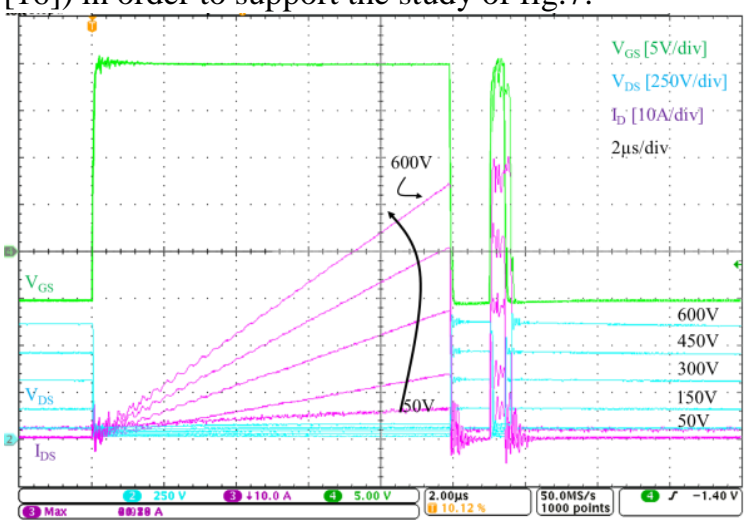

Fig.6. Oscilloscope waveforms under NTO, double pulse and different $\mathrm{V}_{\text {Bus. }} @ 600 \mathrm{~V}, \mathrm{R}_{\mathrm{G}}=10 \Omega, \mathrm{V}_{\text {Drv }}=-5 / 20 \mathrm{~V}$.

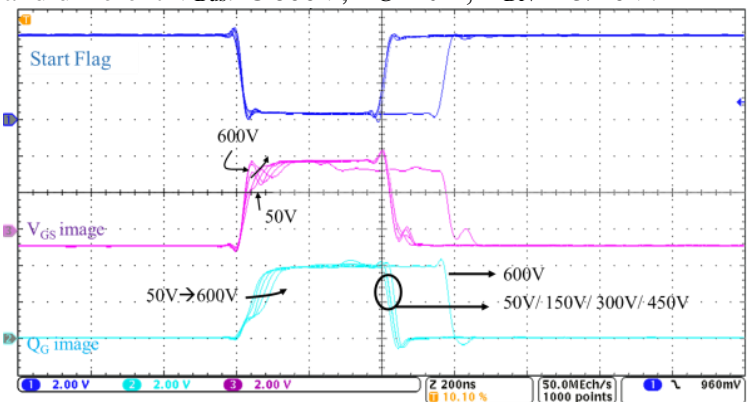

Fig.7. $\mathrm{Q}_{\mathrm{G}}$ and the image of $\mathrm{V}_{\mathrm{GS}}$ oscilloscope waveforms of the second pulse associated to Fig.6, different $V_{\text {Bus }} \& I_{\text {Load. }}$

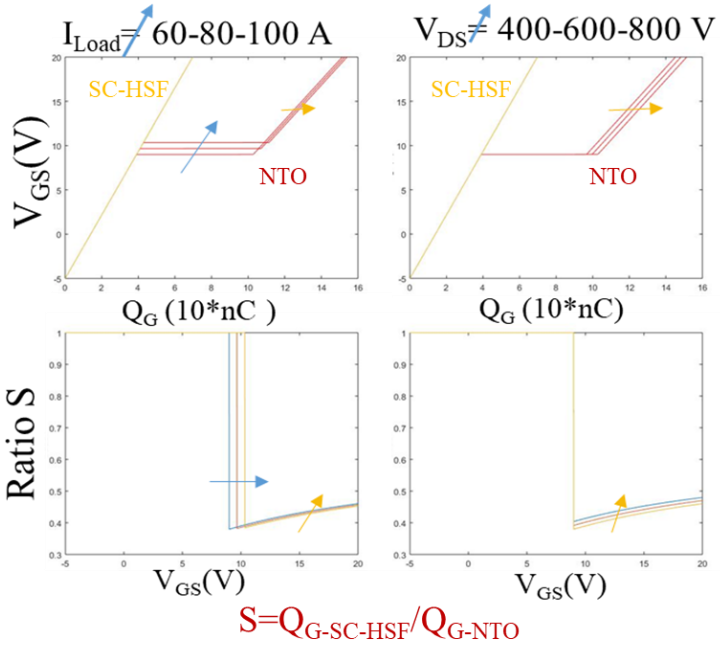

Fig.8. Analytical Gate charge characteristics under different parameters variations. [16]

\section{3. $R_{G}$ variation:}

Fig.9. (a). presents oscilloscope waveforms from the power device side $\left(\mathrm{V}_{\mathrm{DS}}, \mathrm{V}_{\mathrm{GS}}, \mathrm{I}_{\mathrm{D}}\right)$ at $600 \mathrm{~V}$ under NTO and SC-HSF using the same device 'C2M0080120D' with a different external gate resistor $R_{G}=5 \Omega$ (previous tests have been led for $R_{G}=10 \Omega$ ). And Fig.9. (b) illustrate oscilloscope waveforms from the gate charge circuit side, illustrating the gate charge amount and the image of $\mathrm{V}_{\mathrm{GS}}$

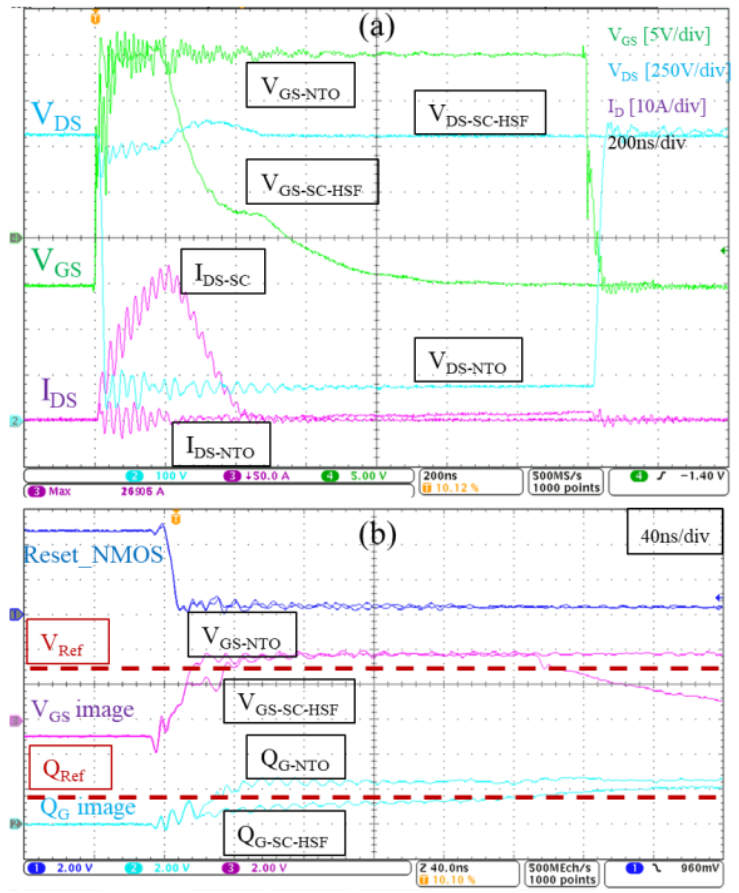

Fig.9. Oscilloscope waveforms under NTO and SC-HSF $@ 600 \mathrm{~V}, \mathrm{R}_{\mathrm{G}}=5 \Omega, \mathrm{V}_{\mathrm{Drv}}=-5 / 20 \mathrm{~V}$.

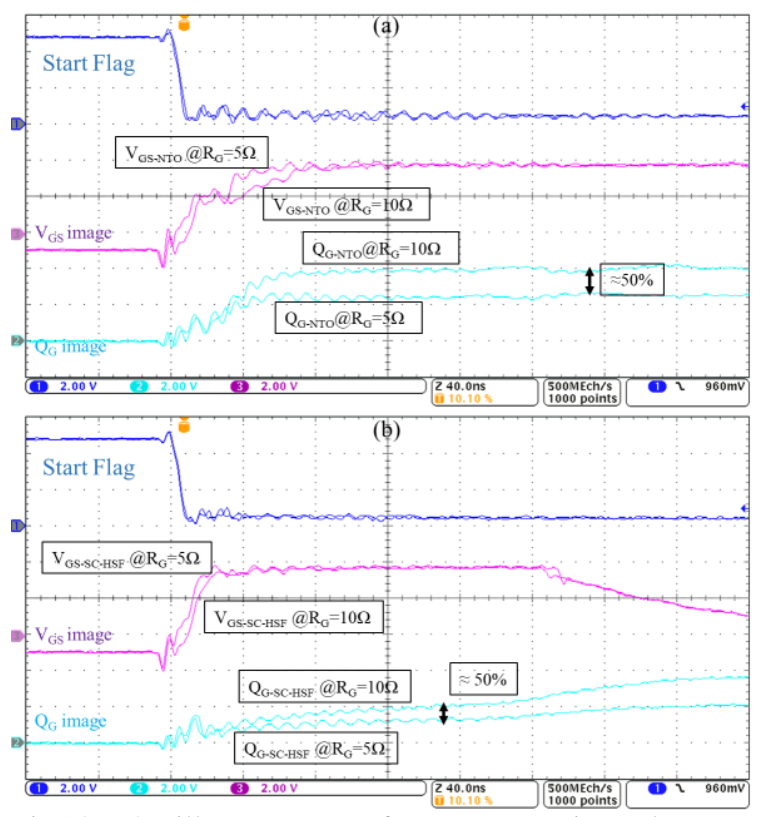

Fig.10. Oscilloscope waveforms comparison between $\mathrm{R}_{\mathrm{G}}=5 \Omega$ and $\mathrm{R}_{\mathrm{G}}=10 \Omega$ under (a). NTO (b). SC-HSF $@ 600 \mathrm{~V}, \mathrm{~V}_{\mathrm{Drv}}=-5 / 20 \mathrm{~V}$.

As one can see the amount of the gate charge is reduced with the reduction of $\mathrm{R}_{\mathrm{G}}$. The reduction is proportional to the created split on $\mathrm{R}_{\mathrm{G}}$, which is around $50 \%$. Mainly, the origin is due to the increase of the Miller plateau indirectly by he increases of $\mathrm{dv} / \mathrm{dt}$ when $\mathrm{R}_{\mathrm{G}}$ is decreased, which decreases the gate charge quantity when $C_{\text {iss }}$ is $\max$ 
and thus $\mathrm{Q}_{\text {Total }}$ is decreased. Fig.10. shows this respective proportionality between the gate resistor values under NTO (a) and SC-HSF(b). Using a gate resistor equal to $5 \Omega$ requires a new set of the gate charge threshold level $\mathrm{Q}_{\mathrm{Ref}}=1.5 \mathrm{~V}$., where, the previous $\mathrm{Q}_{\text {Ref }}$ is equal to $3 \mathrm{~V}$ for $\mathrm{R}_{\mathrm{G}}=10 \Omega$. Therefore, with the new reference set the detection circuit properly detect and protect the device under SC$\mathrm{HSF}$, and does not show any false trigging under NTO. The circuit shows robustness as well for different $\mathrm{dV} / \mathrm{dt}$, in this case $\mathrm{dV} / \mathrm{dt}=36 \mathrm{~V} / \mathrm{ns} @ 600 \mathrm{~V}$. Different bus voltages have been tested as well with a $5 \Omega$ gate resistor.

\subsection{Device generation variation:}

Different devices have been studied in order to set the robustness of the method. In this section a $3^{\text {rd }}$ generation device C3M0065090D is considered. Since the recommended gate to source voltage between both transistor of different generations (G2 $\&$ G3) differ, respectively $-5 / 20 \mathrm{~V}$ and $-4 / 15 \mathrm{~V}$, the reference level $\mathrm{V}_{\mathrm{Ref}}$ should adapt for each generation (and not each transistor), Fig.11. Fig.12 presents the gate charge quantity under SC-HSF and NTO for both components (Gen.II) C2M00800120D device and (Gen.III) C3M0065090D device respectively, Fig.12.a and Fig.12.b. As one can see, the quantity under NTO and SC-HSF for each component is nearly proportional to $42 \%$. The major difference between both component is the total gate charge and the input capacitance of the power device $\mathrm{C}_{\mathrm{iss}}=1.17 \mathrm{nF}, \mathrm{C}_{\mathrm{iss}}=0.76 \mathrm{nF}(-35 \%)$. Therefore, in order to safely protect the device and insure the detection, both references set $\left(\mathrm{Q}_{\mathrm{Ref}}, \mathrm{V}_{\mathrm{Ref}}\right)$ should adapt. In this case $\mathrm{Q}_{\text {Ref }}$ can be set as well at $1.7 \mathrm{~V}$, due the $50 \%$ proportionality between the input capacitances. And, $\mathrm{V}_{\text {Ref }}$ can be set at $2.7 \mathrm{~V}$, instead of $3.3 \mathrm{~V}$ for Gen.II.

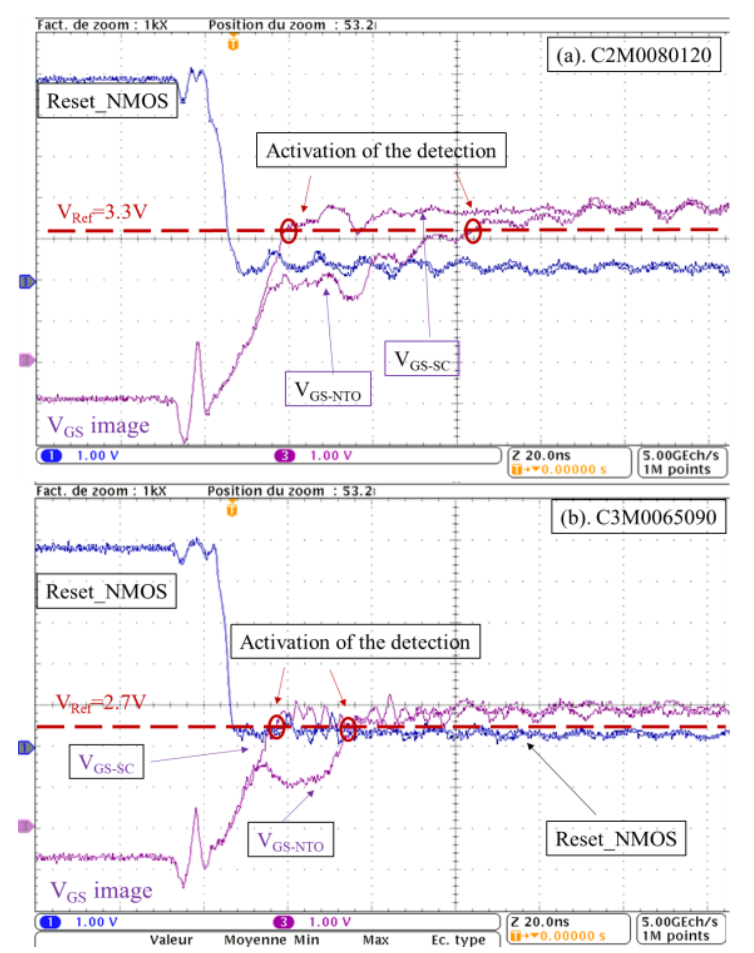

Fig.11. "VGS image" under $400 \mathrm{~V}$ NTO and SC-HSF Barazi et al. - 2021 operation for two power devices, (a). C2M0080120 $\mathrm{V}_{\text {Drv }}=$ $-5 / 20 \mathrm{~V}$ (b).C3M0065090 V Vrv $=-4 / 18 \mathrm{~V}$. @ $\mathrm{R}_{\mathrm{G}}=10 \Omega$. [15].

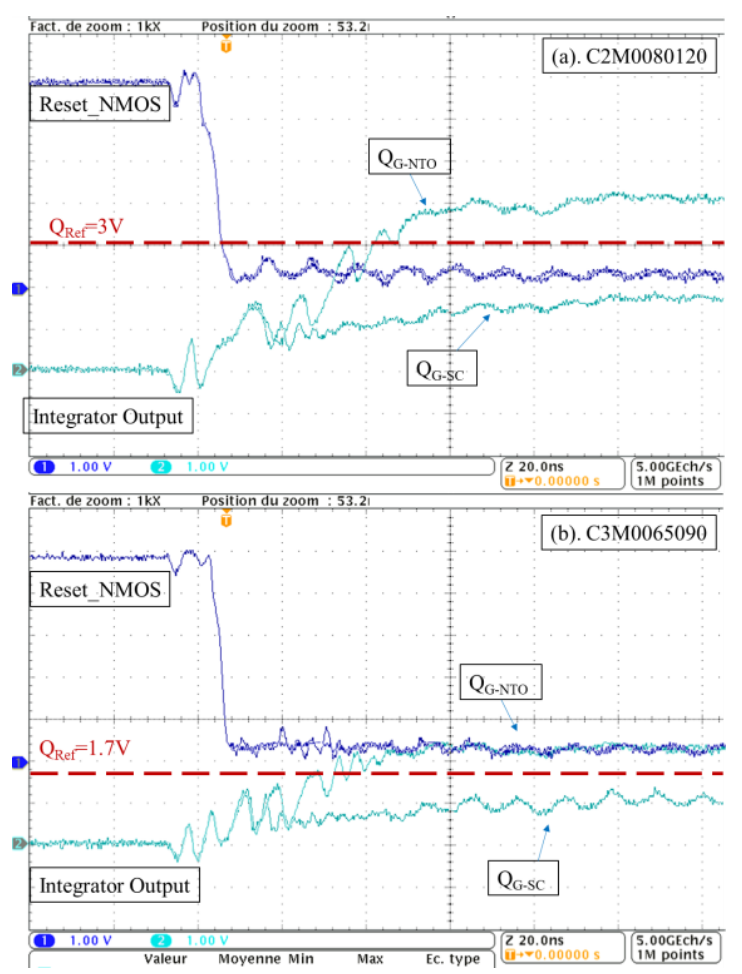

Fig.12.Integrator output "QG" under 400V NTO and SCHSF for two power devices, a).C2M0080120 Viv $=-5 / 20 \mathrm{~V}$ (b).C3M0065090 $\mathrm{V}_{\mathrm{Drv}}=-4 / 18 \mathrm{~V}$. @ $\mathrm{R}_{\mathrm{G}}=10 \Omega$. [15]

\section{Discussion and analysis}

After the detection of a SC fault, the SiC MOSFET must be turned off safely, to limit $\mathrm{I}_{\mathrm{DS}}$ from increasing to a thermal stress point, as well as to avoid dangerous over-voltages. Therefore, to protect the circuit safely, a Soft Shut Down SSD system is included in the circuit. If the protection is not well designed it can lead to breakdown voltage by the total stray inductance due to high negative $\mathrm{dI}_{\mathrm{DS}} / \mathrm{dt}$ imposed by the transistor's channel dynamic, the protection should be soft to prevent this phenomenon. A high impedance (HZ) state is required before the activation of the SSD to avoid the driver to be short circuited by the SSD circuit. The observed plateau in the gate-source voltage $\mathrm{V}_{\mathrm{GS}}$ under protection is due to the inductive effect through the kelvin inductance $\mathrm{L}_{\mathrm{SK}}$ (parasitic inductance of package and terminal pin on PCB in the presence of a di $/ \mathrm{dt}<0$ ).

The protection is activated between 150ns and 180ns depending on the test condition, limiting the drain current around 110A - 151A instead of respectively $130 \mathrm{~A}$ - 220A. In such a short time and at such a low current value, the dynamic temperature of the chip remains lower than the melting temperature of the aluminum to metal of the die, which would allow a large number of repeated short circuits without ageing effect [17]. One should note that optimization can be realized in order to protect earlier and limiting the drain current to lower value, therefore reducing furthermore the physical and 
thermal stress on the device.

The robustness of the circuit has been tested for several pulses, $V_{D S}$ values, $I_{\text {load }}$ values, $R_{G}$ values and different components. Detection at lower bus voltages is more critical between SC-HSF and NTO, where the circuit showed high performances at $50 \mathrm{~V}$ and lower.

Regarding the gate side variation, a different threshold set is required for values higher than $50 \%$ of the defined gate charge amount. On the other hand, one can set a trade-off between the integrator capacitor/resistor $\left(\mathrm{C}_{1} / \mathrm{R}_{1}\right)$ and the gate resistor/gate input capacitance of the device $\left(\mathrm{R}_{\mathrm{G}} / \mathrm{C}_{\mathrm{Eq}}\right)$. Fig.13. presents a 3D plot of the output of the integrator, $\mathrm{V}_{\text {Out }}$, under different variation, where this trade-off can be met. On the figure, two representative equivalent capacitors define a plateau of $C_{1} / R_{1}$ choices. The equivalent capacitors represent the input capacitance of the power device under NTO and SC-HSF. Since the gate charge amount ratio under NTO and SC-HSF is $50 \%$, the same ratio is respected for the equivalent capacitors. Therefore, the one can easily define the threshold set $\mathrm{Q}_{\mathrm{Ref}}$ in order to differentiate between NTO and SC-HSF gate charge amount. As well, one can define different family sets for the gate variations (Gate resistor, input capacitance) in order to have a programmable threshold level set.

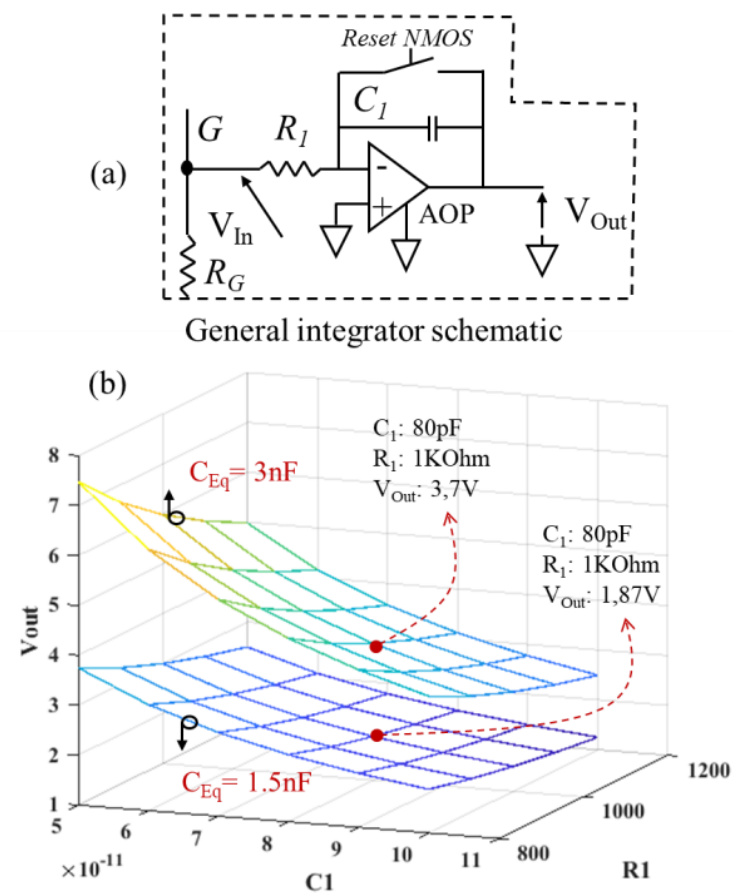

Fig.13. (a). Basic integrator schematic (b). 3D plot of the integrator output $V_{\text {Out }}$ under different variation. [16], with $\mathrm{R}_{1} \gg>\mathrm{R}_{\mathrm{G}} \& \mathrm{C}_{1}>>\mathrm{C}_{\text {Stray }}$

\section{Conclusion}

2D diagnosis once again proves it is the perfect candidate for fast short-circuit detection and protection. The original gate-charge method (2D diagnosis) detects as fast as possible the behavior of the circuit, within 155ns. High robustness have been observed for main parameters variations. Moreover,

Barazi et al. - 2021 the detection circuit can be further optimized and the delays can be strongly reduced. At the end, the goal is to integrate all the functions in a dedicated gate driver. Avoiding the drain side of the device facilitate the integration of the detection method within the gate driver. A programmable reference set should be carefully designed.

\section{References}

[1] Baliga B.J.: Silicon Carbide Power Devices, World Scientific, 2005.

[2] Wang Z., et al.: Design and Performance Evaluation of Overcurrent Protection Schemes for Silicon Carbide ( $\mathrm{SiC}$ ) Power MOSFETs, IEEE TIEs 61, 5570-5581 (2014).

[3] Romano G., et al.: Influence of design parameters on the short-circuit ruggedness of SiC power MOSFETs, in 2016 28th ISPSD, juin 2016, p. 4750,

[4] Chen J., et al.: A Smart IGBT Gate Driver IC with Temperature Compensated Collector Current Sensing, in IEEE Transactions on Power Electronics, vol. 34, no. 5, pp. 4613-4627, May 2019.

[5] Sadik D., et al.: Short-Circuit Protection Circuits for Silicon-Carbide Power Transistors, in IEEE Transactions on Industrial Electronics, vol. 63, no. 4,pp. 1995-2004.

[6] Awwad A. E., Dieckerhoff S.: Short-circuit evaluation and overcurrent protection for SiC power MOSFETs, 2015 17th EPE'15 ECCE-Europe, Geneva, 2015, pp. 1-9.

[7] Bertelshofer T., Maerz A., Bakran M.: Design Rules to Adapt the Desaturation Detection for SiC MOSFET Modules, PCIM Europe 2017, Nuremberg, Germany.

[8] Bakran M., Hain S.: Integrating the New 2D - Short circuit detection method into a power module with a power supply fed by the gate voltage, 2016 IEEE (SPEC), Auckland, 2016, pp. 1-6.

[9] Oberdieck K., Schuch S., DeDoncker R. W.: "Short circuit detection using the gate charge characteristic for Trench/Fieldstop-IGBTs", EPE'16 ECCE Europe, Karlsruhe, 2016, pp. 1-10.

[10] Horiguchi T., Kinouchi S., Nakayama Y., Akagi H.: A fast short-circuit protection method using gate charge characteristics of SiC MOSFETs, 2015 IEEE ECCE, Montreal, QC, 2015, pp. 4759-4764.

[11] Paula Diaz Reigosa, Francesco Iannuzzo, Lorenzo Ceccarelli, Effect of short-circuit stress on the degradation of the $\mathrm{SiO} 2$ dielectric in $\mathrm{SiC}$ power MOSFETs, Microelectronics Reliability, Volumes 88-90, 2018.

[12] Dou, Zhifeng. Sûreté de fonctionnement des convertisseurs - Nouvelles structures de redondances pour onduleurs sécurisés à tolérance de pannes. $\mathrm{PhD}$, Institut National Polytechnique de Toulouse, 2011.

[13] D. Othman, 'Etude d'interrupteurs en carbure de silicium et potentiel d'utilisation dans des applications aéronautiques', PhD, Paris Saclay, 2015.

[14] Y. Barazi, N. Rouger, F. Richardeau: Comparison between ig integration and vgs derivation methods dedicated to fast short circuit 2D diagnosis for wide band gap power devices, Mathematics and Computers in Simulation, 2020.

[15] Y. Barazi, F. Boige, N. Rouger, J. -M. Blaquiere and F. Richardeau, "'ig,vgs' Monitoring for Fast and Robust SiC MOSFET Short-Circuit Protection with High integration Capability," 2020 22nd European Conference on Power Electronics and Applications (EPE'20 ECCE Europe), Lyon, France, 2020, pp. P.1-P.10,

[16] Y.Barazi, 'Fast short-circuit protection for $\mathrm{SiC}$ MOSFETs in extreme short-circuit conditions by integrated functions in CMOS-ASIC technology', $\mathrm{PhD}$, 
Laplace, INPT,2020.

[17] Fayyaz A., Boige F., Borghese A., Guibaud G., Chazal V., et al.: Aging and failure mechanisms of $\mathrm{SiC}$ Power MOSFETs under repetitive short- circuit pulses of different duration, ICSCRM 2019, Japan 